\title{
Quantitative Analysis of the Impact of Urban Labor Productivity on the Economic Corridor of Bangladesh, China, India and Myanmar
}

\author{
Panpan $\mathrm{Wu}$ \\ Yunnan University of Finance, \\ Economics Economic Research Institute \\ Kunming,China \\ 2608278021@qq.com
}

\author{
Yaqin $\mathrm{Lu}^{*}$ \\ Yunnan University of Finance, \\ Economics Economic Research Institute \\ Kunming,China \\ luyaqinhuan@126.com
}

\begin{abstract}
In 2009, the World Bank proposed the "3D" analysis framework, namely density, distance and division. Based on the theoretical framework, this paper uses the provincial state data of the countries along the Bangladesh, China, India, and Myanmar Economic Corridor from 2004 to 2014 to analyze the effects of density, distance, and division indices on urban labor productivity. The study found that there is significant spatial autocorrelation between the states of the countries along the BCIM economic corridor, and that the output density, the actual use of foreign capital, and distance have a significant impact on the difference in urban labor productivity, which is in line with expectations. Among them, output density has a significant positive effect on urban labor productivity, and division and distance have a significant negative effect on labor productivity.
\end{abstract}

Keywords - Bangladesh; China; India and Myanmar economic corridor; Density; distance; division; labor productivity; spatial empirical methods

\section{INTRODUCTION}

Since the 21st century, with the continuous development of economic globalization and regional integration, developing countries have increasingly attached importance to the construction of cross-border economic corridors. In September 2014, President Xi Jinping proposed to accelerate the construction of the BCIM economic corridor. The core areas of the BCIM Economic Corridor include the narrow economic belts in the southwestern part of China (Chongqing, Sichuan, Yunnan and Guangxi provinces and cities), West Bengal and northeastern India, northern and central Myanmar and Bangladesh. The region has huge potential in connection with the three major markets of South Asia, Southeast Asia, and East Asia. It is an important part of the construction of the South China Silk Road Economic Belt in the "Belt and Road" strategy of China, and has an important strategic position.

The BCIM Economic Corridor is a key section of the New South Silk Road and is a powerful way to promote the development of the "One Belt and One Road" to achieve regional integration and a new engine for regional inclusive growth. Although the construction of the BCIM Economic Corridor has yielded fruitful results, cooperation is still in its

*Corresponding author infancy and no substantial breakthrough has been achieved, mainly due to the lack of a dynamic mechanism for growth integration in the region. In all areas, infrastructure along the BCIM Economic Corridor is relatively weak for economic development, low levels of economic agglomeration, complex ethnic and religious backgrounds, political turmoil in some countries, and a lack of political mutual trust resulting from conflicts of interest, making the area of cooperation on economic and geographical structure lacks effectiveness. How to increase economic density, shorten distance, and integrate integration have become the core issues in the BCIM Economic Corridor promotion mechanism. Therefore, this paper uses the 3D theoretical framework of the World Bank's 2009 Development Report "Reshape the Economic Geography of the World" to reshape the global economic geography to explore the differences in the labor productivity of the provinces and states of the BCIM Economic Corridor in order to further promote the construction provides theoretical basis and policy recommendations.

\section{LITERATURE REVIEW}

Since Yunnan scholars first proposed economic cooperation between Bangladesh, China, India and Myanmar in 1991, scholars have conducted extensive research on them, and the establishment of the Bangladesh, China, India, and Myanmar Economic Corridor has become the focus of multidisciplinary research. Wen Fude [1], on the basis of expounding the meaning of the Bangladesh-China-Burmese Economic Corridor, focused on the necessity of economic significance, social significance, and safety significance of the Bangladesh-China-Burma-Myanmar Economic Corridor; Yin Yonglin [2]; Li Jianjun,Wang Hongyi [3]; Huang Dekai [4] analyzed the status quo, challenges and countermeasures of the construction of the Bangladesh-China--India-Myanmar Economic Corridor; Chen Lijun [5] proposed the prospects and countermeasures for the construction of the Bangladesh-ChinaIndian-Myanmar Economic Corridor. Lin Yanming [6] discussed the importance and influence of the location characteristics, degree of openness and willingness to open in the northeast region of India on the construction of the Bangladesh-China-India-Myanmar Economic Corridor. In 
addition, in terms of economics, Liang Shuanglu and Liang Qiaoling [7] are based on the international division of labor in the industry. The layout has studied the Economic Corridor of Bangladesh, China India and Myanmar.

On the empirical side, Mark Roberts and Chor-ching Goh [8] used the city data of Chongqing of China from 2000 to 2007 to explain the differences in labor productivity among counties in the municipalities under the jurisdiction of Chongqing in the framework of 3D analysis, and to obtain distance-to-space productivity. The difference has a significant effect, especially in the southeast wing of the municipality. Jinhwan oh [9] based on the spatially adjusted MSV model and taking Korea as an example, analyzed the three stages of urbanization that correspond to the three stages of industrial development: poverty traps, partial industrialization, and overall industrialization. In the same way as the study by Brlhart et al. [10] on EU countries. In China, Yu Jie, Liu Yong, and Liu Xiuhua [11] analyzed the economic growth differences in Chengdu-Chongqing Economic Zone based on the 3D framework. Research shows that the density effect is significantly positive and the distance is negative. The urbanization rate of household registration is used as a measure of division. The impact on economic growth is significantly positive, and some scholars have added diversity or specificity to $3 \mathrm{D}$ and expanded into 4D [12]. In addition, many scholars have applied the 3D analysis framework to the study of economic spatial evolution[13][14].

Through the above review, the research on the economic corridor of Bangladesh, China, India and Myanmar has yielded rich results, providing theoretical support for this article. Based on the basic theory of new economic geography and the 3D analysis framework propose "World Development Report" in the 2009, this paper discusses the differences in the labor productivity of the provinces and states of Bangladesh, China, India, and Myanmar Economic Corridor, and the influencing factors, and explores ways and methods for promoting the construction of the Bangladesh-China-India-Burmese Economic Corridor. Then, in the world's less developed countries or regions, a new model of international regional growth integration has been extracted.

\section{VARIABLE AND DATA SELECTION}

In 2009, the World Bank issued the "World Development Report 2009: Reshaping the World Economic Geography" (hereinafter referred to as "WDR") to put forward a 3D analysis framework, clearly demonstrating the impact of 3D indicators on national or regional agglomeration economies. The 3D framework consists of density, distance and division (and therefore 3D terminology).

\section{A. Density}

Density-the degree of agglomeration of economic activity per unit of land, is a spatial representation of agglomeration economies. For producers, it has both positive and negative effects on economic efficiency. The positive effect refers to the fact that companies are located in areas where activity is concentrated, so that companies have greater market potential, and companies enjoy positive externalities, which benefits them a lot. The negative effect means that when the economic density is too high and the crowding effect is greater than the agglomeration income, the land and labor costs will rise, leading to an increase in urban operating costs, and the urban labor productivity will decrease. For the measurement of economic density, different scholars use different metrics, some use employment density, population density, and some use output density. Taking into account the differences in national statistical calibers, this paper chooses output density to measure.

\section{B. Distance}

Distance mainly describes the relationship between the economic agglomeration effect and the geographical location of the activity center. Some of them overlap with the concept of density. This is because high density in itself means that the distance is minimized. There are also positive and negative effects on economic efficiency. Positive effects mean that companies avoid polarization due to their proximity to highdensity areas; negative effects mean that because of the distance from economic activity agglomeration centers, market transportation costs increase and they cannot enjoy the knowledge and technology spillover externality dividend, resulting in reduced productivity. . Considering the availability of cross-country distance data, this paper formulates distances from the proposed sample city to its capital city for distance calculation:

$$
\mathrm{d}=\mathrm{c} \sqrt{\left(\mathrm{x}_{1}-\mathrm{x}_{2}\right)^{2}+\left(\mathrm{y}_{1}-\mathrm{y}_{2}\right)^{2}}
$$

In the (1), c is a constant, and the value is 111.111 , which represents the coefficient of the surface coordinate unit of the sphere (degree converted into a planar distance (KM)); $(\mathrm{x} 1, \mathrm{y} 1)$ represents the latitude and longitude of a certain city, and $(\mathrm{x} 2, \mathrm{y} 2)$ represents the latitude and longitude of the capital city of a certain country.

\section{Division}

Division is a barrier to economic interactions such as currency, language differences and tariffs, which limits market access. The higher the market division along the BangladeshChina-India-Myanmar Economic Corridor, the higher the transportation cost and the cost of goods flow; the lower the degree of trade facilitation, it will hinder the increase of labor productivity in the city. This article selects the actual use of foreign capital by provincial states to measure the impact of splitting on urban labor productivity in the region. The expected effect is negative. It shows that the higher the amount of foreign capital actually used, the higher the level of market opening to the outside world, the smaller the degree of division, and the higher the labor productivity. On the contrary, the opposite is true.

\section{Spatial ANALYSis}

According to the new economic geography and spatial econometrics theory, the spatial dependence of regional economic development is analyzed by analyzing spatial autocorrelation. Using spatial economic exploration methods, the paper analyzes the spatial correlation of labor productivity 
in countries along the Bangladesh-China-India-Myanmar Economic Corridor, and closely follows the relationship between the 3D indicators of Bangladesh, China, and Myanmar and the labor productivity of cities.

\section{A. Spatial Autocorrelation Test Of Urban Labor Productivity}

In this paper, the most widely used Moran's I statistic is used to determine the spatial correlation of variables, Moran's $\mathrm{I} \in[-1,1]$. The closer $\mathrm{I}$ is to 1 , the stronger is the degree of positive correlation between regions; on the contrary, the stronger is the degree of negative correlation; close to 0 means there is no spatial autocorrelation between regions.

Due to the availability of data, this paper only selected 15 provincial states along the Bangladesh-China-India-Myanmar Economic Corridor, including mainly Chongqing, Sichuan, Yunnan, and Guangxi in the southwestern part of China; Northeast India and West Bengal in India; and Myanmar's largest city. The average of data from 2004 to 2014 in Yangon and the largest port city of Bangladesh, Chittagong, was used to analyze the global autocorrelation analysis of the state states along the Bangladesh-China-India-Myanmar Economic Corridor, to observe the arrangement and distribution patterns of observations in this region. Figures 1 show the global Moran's I index of labor productivity measured by non-farm wages in the 15 provincial states along the Bangladesh-ChinaIndia-Myanmar Economic Corridor and their inspections. The analysis results show that Moran's I is 0.76 , the $\mathrm{Z}$ value is 4.87 , and the $\mathrm{P}$ value is 0.02 , which means that the significance level is significant at 5\%, which further shows that there is agglomeration in the region and it shows high and low accumulation. Through the above analysis, it is fully proved that there is a spatial correlation between observational data, and it is obviously unreasonable to use traditional econometrics. So this paper uses spatial econometric analysis.

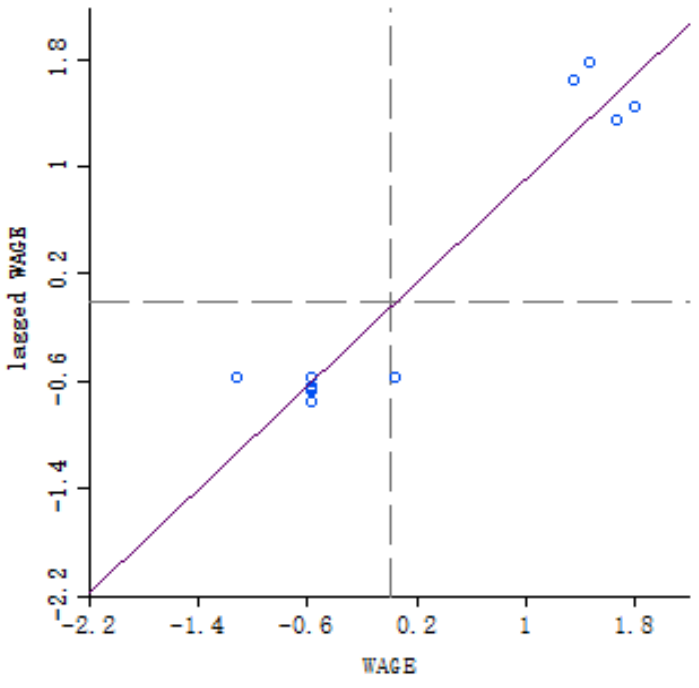

Fig. 1. Moran's I:0.768652

\section{B. Spatial Econometric Analysis}

According to the GeoDa software's analysis of the regression results, we first look at whether the LM-lag and
LM-error pass the significance test. If not, use the OLS model. If there is only one significant test, the spatial regression model corresponding to the significance test is selected. If both are significant, further consider Robust LM-lag and Robust LMerror, judgment method and selection LM-lag. Consistent with LM-error.TABLE I shows the spatial autocorrelation statistic test results for the data from 2004 to 2014

TABLE I. LM, ROBUST LM TEST

\begin{tabular}{|c|c|c|}
\hline Test statistics & coefficient & P-value \\
\hline LM(lag) & 8.23 & 0.004 \\
\hline Robust LM(lag) & 8.29 & 0.003 \\
\hline LM(error) & 2.20 & 0.138 \\
\hline Robust LM(error) & 2.26 & 0.133 \\
\hline
\end{tabular}

In TABLE I, the P values of LM-lag and LM-error are 0.004 and 0.138 , respectively, and LM-lag passes the significance test at a $1 \%$ significance level. Therefore, the spatial lag model is used to re-estimate the results. For ease of comparison, two model regression results are listed: the OLS model (without considering the spatial spillover effect estimation results) and the spatial lag model (taking into account the spatial spillover effect estimation results).

TABLE II. ESTIMATION RESULTS OF OLS MODEL AND SLM

\begin{tabular}{|c|c|c|}
\hline \multirow{2}{*}{ Independent variable } & \multicolumn{2}{|c|}{ LN_WAGE } \\
\hline & OLS Model & $S L M$ \\
\hline Constant & 2.79 & -0.15 \\
\hline LN_Density & $0.32^{\circ} \mathrm{a}$ & $0.39^{4 * 4}$ \\
\hline LN_Division & $-0.56^{\circ b} b$ & $-0.37^{\text {क्w }} \mathrm{c}$ \\
\hline LN_Distance & -0.86 & $-0.61^{4 * 4}$ \\
\hline W_LN_WAGE & $\longrightarrow$ & $0.58^{4+4}$ \\
\hline $\mathrm{R}^{2}$ & 0.61 & 0.83 \\
\hline Log Likelihood & -11.61 & -6.61 \\
\hline AIC & 31.21 & 23.21 \\
\hline SC & 34.04 & 26.75 \\
\hline
\end{tabular}

Comparing the two regression results, it is found that in the spatial lag model, when the output density increases by $1 \%$, the urban labor productivity increases by $0.39 \%$; when the division measured by actual use of foreign capital increases by $1 \%$, the urban labor productivity decreases by $0.37 \%$. As the distance increases by $1 \mathrm{~km}$, the labor productivity in the city decreases by $0.61 \%$. Comparing the two regression results, we found that the significance of each variable significantly increased, R2 and Log Likelihood increased, the W_LN_WAGE coefficient was less than 1 , satisfying the robustness requirement, and the AIC and SC decreased, reflecting the advantages of the spatial lag model over traditional econometrics. In the economic space, 
China's four southwestern provinces are adjacent to neighboring countries by land and sea, linking Southeast Asia, South Asia, and other export markets, providing convenience for Bangladesh, China, India, and the Four Kingdoms.

\section{CONCLUSIONS AND POLICY RECOMMENDATIONS}

This article uses the cross-sectional data of the state-state averages of various countries from 2004 to 2014 to select three indicators: output density, actual use of foreign capital, and the latitude and longitude distance of a city to its capital city, to analyze the impact of 3D indicators on urban labor productivity. Through analysis we have reached the following conclusions: First, there is a significant spatial autocorrelation between the states of the countries along the BCIM economic corridor, showing high-high agglomeration and low-low agglomeration states. Cities with higher labor productivity are surrounded by cities with higher labor productivity; secondly, by using the OLS model and spatial econometric model to analyze the relationship between $3 \mathrm{D}$ indicators and urban labor productivity, both models show output density and actual use of foreign capital. The distance has a significant effect on the difference in urban labor productivity and is in line with expectations. Among them, output density has a significant positive effect on urban labor productivity, and segmentation and distance have a significant negative effect on labor productivity. Finally, by comparing the results of the two regressions, we find that the variables that take into account spatial dependence have a significant increase in urban labor productivity, and that the estimated coefficients of the traditional econometric models change in absolute value. Specifically, the coefficient of output density rises, distance and division coefficient decrease, R2 and Log Likelihood increase, and AIC and SC decrease, indicating that the lag model of adding space better reflects the impact of 3D index on urban labor productivity.

Based on the above conclusions, the following suggestions are made to further promote the construction of the Bangla desh China Burmese Economic Corridor: First, the four countries of Bangladesh, India, and Myanmar must strengthen organizational leadership, deepen regional economic cooperation, increase density, increase industrial cooperation, increase the level of opening up, and facilitate trade and investment. To jointly enhance regional economic competitiveness; second, Bangladesh, China, India, and Myanmar must strengthen and improve infrastructure construction, shorten the distance from the use of the advantages of neighboring countries, focus on strengthening transport infrastructure, port construction, and promote the establishment of a customs coordination mechanism to improve transport efficiency in order to reduce cross-border trade costs and create a good environment for cooperation. Third, China, as an advocate of the Bangladesh-China-India-
Myanmar economic corridor, should adopt a policy of subadvancement under the predicament of multilaterally difficult advancement, first to first, from China to India or ChinaBangladesh. Starting from the cooperation, the development of the BCIM Economic Corridor will proceed from "bilateral advancement" to "multilateral advancement" with a view to eventual integration of regional economic cooperation. Fourth, as the "window" for China to advance the BCIM economic corridor, the four provinces in southwest China should take advantage of the trend to formulate an outward-oriented industrial policy, enhance their radiation capacity, and encourage "going out" actions.

\section{REFERENCES}

[1] Wen Fude, Necessity analysis of the construction of the economic corridor between Bangladesh,China, India, and Myanmar, Indian Ocean Economy, 2014, (1): 122-128.

[2] Yin Yonglin, Line studies of the economic corridor of Bangladesh, China, India, and Myanmar, Yunnan Social Sciences, 2016, (1): 73-77.

[3] Li Jianjun, Wang Hongyi, The status quo and challenges of economic development in Bangladesh, South Asia Research Quarterly, 2012(3):52-58.

[4] Huang Dekai, Yan Ke, Status quo, difficulties and countermeasures of non-traditional security cooperation in the economic corridor of Bangladesh, China, India and Burma, Indian Ocean Economic Research, 2016(2):28-41.

[5] Chen Lijun, Prospects and countermeasures for the construction of Bangladesh, China, India and Myanmar Economic Corridor, Yunnan Social Sciences, 2014, (1): 1-6.

[6] Lin Yanming, Northeast India and Bangladesh, India, and Myanmar Economic Corridor, Southeast Asia, South Asia Study, 2015, (3): 8-17.

[7] Liang Shuanglu, Liang Qiaoling, How to speed up the construction of Bangladesh, China, India, and Myanmar Economic Corridor under the "New Belt and Road" approach - Research based on the international division of labor and layout of the industry, 2015, (5): 145-149.

[8] Mark R, Chorching G, Density, distance and division: the case of Chongqing municipality of China , Cambridge Journal of Regions,2011, (6) :1-16.

[9] Jinhwan O H. Spatial adaptation of the MSV model, with spatial reference to World Development Report 2009 and korean example, Letters in Spatial and Resource, 2011,5 (1) :33-45.

[10] Brulhart M, Mathys N A. Sectoral agglomeration economies in a panel of European regions[J].Journal of Urban Economics,1986 , 20 (2) :211-228

[11] Yu Jie, Liu Yong, Liu Xiuhua, Study on economic growth differences of Chengdu-Chongqing Economic Zone based on "3D" framework, 2016 , (10): 90-96.

[12] Zhang Xiaohuan, Shen Tiyan, Chang Xu, County Economy in Perspective of “4D”, Open Guide, 2013, (1): 105-108.

[13] Wang Jieyu,Huang Zhiji, Economic spatial analysis of Beijing-Tianjinwing metropolitan area based on $3 \mathrm{D}$ perspective, Urban Observation, 2012, (3): 67-76.

[14] Chen Xiaofei, Ji Lili, Zhang Luocheng, Zhao Jinli, Spatial evolution of economic geography of prefecture-level cities in Jiangsu Province based on the "3D" framework, Geography and Geographical Information Science, 2014,(3):66-70. 